\title{
MULHERES E A PESCA ARTESANAL: SALVAGUARDANDO CONHECIMENTOS TRADICIONAIS SOBRE PLANTAS DA RESTINGA EM ARRAIAL DO CABO, BRASIL
}

\author{
WOMEN AND ARTISANAL FISHING: SAFEGUARDING TRADITIONAL \\ KNOWLEDGE ABOUT RESTINGA PLANTS IN ARRAIAL DO CABO, BRAZIL
}

Nicky van LUIJK ${ }^{1 *}$; Zenilda Maria da SILVA²; Maria Helena de Oliveira e SILVA²; Viviane Stern da FONSECA-KRUEL ${ }^{3}$.

${ }^{1}$ Programa de Pós-Graduação em Biodiversidade em Unidades de Conservação, Escola Nacional de Botânica Tropical/JBRJ, RJ, Brasil. ${ }^{2}$ Cooperativa de Pesca Mulheres Nativas, Arraial do Cabo, RJ, Brasil. ${ }^{3}$ Instituto de Pesquisas Jardim Botânico do Rio de Janeiro, RJ, Brasil. *luijk.nv@gmail.com

Submitted: 15/11/2020; Accepted: 03/02/2021; Published: 06/04/2021

\section{RESUMO}

A pesca artesanal é o principal meio de sobrevivência para cerca de 39 milhões de pessoas no mundo. As mulheres representam $50 \%$ da força de trabalho nos setores de pré e pós-captura, no entanto, seguem na invisibilidade. Tal espaço de labor ainda é majoritariamente masculino, tanto que no Brasil meio milhão de trabalhadoras da pesca continuam marginalizadas devido ao preconceito de gênero, ainda que sejam detentoras de conhecimentos que garantem a sobrevivência de suas famílias, como em Arraial do Cabo (RJ). O estudo, nesse contexto, objetivou investigar o papel delas nas atividades pesqueiras realizadas pela comunidade tradicional do município - uma das mais antigas e importantes do estado do Rio de Janeiro -, assim como seus conhecimentos sobre as plantas da restinga utilizadas na pesca, especialmente entre os períodos compreendidos entre 1940-1960 e a partir de 1990 até hoje. Para tal, foram realizados levantamentos bibliográficos sobre a história da região e entrevistas com duas nativas, cujos dados demonstraram que em décadas passadas elas eram responsáveis pelo beneficiamento do pescado através da salga, serviço remunerado por donos de paióis e tido como secundário. Hoje em dia elas atuam na captura, no beneficiamento e na confecção de diversos produtos - à base de peixe - para comercialização. Tais tarefas indicam que o papel da mulher na atividade pesqueira vem sofrendo mudanças. Ademais, elas detêm conhecimentos importantes quanto à segurança alimentar, os recursos pesqueiros e a flora da restinga, bem como sobre frutos nativos e o preparo de alimentos locais.

PALAVRAS-CHAVE: Etnobiologia, Gênero, Pesca tradicional, Recursos marinhos, Restinga.

\begin{abstract}
Artisanal fishing is the main means of survival for some 39 million people worldwide. Women represent $50 \%$ of the workforce in the pre- and post-capture sectors, however, they remain invisible. Such work space is still mostly male, so that in Brazil half a million fishermen remain marginalized due to gender prejudice, even though they have knowledge that guarantees the survival of their families, as in Arraial do Cabo (RJ). The study, in this context, aimed to investigate their role in fishing activities carried out by the traditional community of the municipality - one of the oldest and most important in the state of Rio de Janeiro -, as well as their knowledge of restinga plants used in fishing, especially among the periods between 1940-1960 and from 1990 until today. To this end, bibliographical surveys on the history of the region and interviews with two natives were carried out, whose data showed that in past decades they were responsible for the fish processing through
\end{abstract}


LUIJK, N. et al. Mulheres e a pesca artesanal: salvaguardando conhecimentos tradicionais sobre plantas da restinga em Arraial do Cabo, Brasil. Ethnoscientia v.6 n. 2, especial, 2021. DOI: 10.22276/ethnoscientia.v6i2.388

salting, a service paid by owners of storerooms and had as a secondary. Nowadays they act in the capture, the processing and the confection of diverse products - based on fish - for commercialization. Such tasks indicate that the role of women in fishing has been changing. In addition, they have important knowledge regarding food security, fishing resources and restinga flora, as well as native fruits and the preparation of local foods.

KEYWORDS: Ethnobiology, Gender, Traditional fishing, Marine resources, Restinga.

\section{INTRODUÇÃO}

A pesca artesanal é o principal meio de sobrevivência para cerca de 39 milhões de pessoas no mundo, sendo fonte primária na alimentação de diversas comunidades (FAO, 2020). As mulheres desempenham importante papel nessa atividade, especialmente na pesca costeira de pequena escala, atuando ao longo de toda a cadeia de produção (ZHAO et al., 2013). Elas contribuem significativamente para a subsistência familiar e para a indústria, representando $50 \%$ da força de trabalho nos setores de pré e pós-captura, porém apenas $12 \%$ na produção primária (FAO, 2020).

Apesar das relevantes contribuições, a situação feminina no Brasil é alarmante: meio milhão de mulheres vivem da pesca artesanal, mas seguem em situação de marginalização, ainda que detentoras de conhecimentos relacionados às estratégias de sobrevivência, especialmente na alimentação e saúde (WOORTMANN, 1992). Tal marginalização ocorre, em grande parte, devido à herança de determinados valores culturais, como a segregação por gênero nos afazeres cotidianos, nos quais as "atividades femininas" estão associadas à costa (e.g. extrativismo de crustáceos e moluscos) e ao lar, e as "masculinas" ao mar e ao trabalho fora de casa (WOORTMANN, 1992; LINKSER e TASSARA, 2005; MARTINEZ e HELLEBRANT, 2019; SOUZA et al., 2019).

De acordo com a FAO (2016), 90 milhões de trabalhadoras da pesca permanecem na invisibilidade para os gestores de políticas públicas e tomadores de decisão, fato que tem gerado prejuízos como condições insalubres de trabalho, dificuldade na obtenção de direitos ocupacionais, baixa remuneração e o não reconhecimento da contribuição econômica em estatísticas oficiais. Há pouca valorização de suas funções na pesca profissional, apesar delas serem decisivas na nutrição e geração da renda familiar, especialmente na América do Sul e no Brasil (HARPER, 2013; SOUZA et al., 2019; FAO, 2020). É valido ressaltar que as mulheres desempenham relevante trabalho no beneficiamento pesqueiro nacional, porém tampouco são reconhecidas nas comunidades tradicionais brasileiras como profissionais, o que dificulta a obtenção de direitos como carteira de pescadora, seguro defeso e 
LUIJK, N. et al. Mulheres e a pesca artesanal: salvaguardando conhecimentos tradicionais sobre plantas da restinga em Arraial do Cabo, Brasil. Ethnoscientia v.6 n. 2, especial, 2021. DOI: 10.22276/ethnoscientia.v6i2.388

aposentadoria (WOORTMANN, 1992; LINKSER e TASSARA, 2005; SOUZA et al., 2019; BRITO, 2019).

Diversos estudos vêm sendo realizados, há décadas, sobre o viés de gênero e a questão das mulheres na pesca artesanal em comunidades costeiras, evidenciando que são percebidas como auxiliares do homem e não protagonistas, destacando ainda, em alguns casos, que suas atividades estão associadas à dimensão emocional e não financeira, assim como ao lazer e à extensão dos cuidados domésticos (FONTENELLE, 1960; YODANIS, 2000; WILLIAMS, 2008; FRANGOUDES e KEROMNES, 2008; MENDES e PARENTE, 2016; FONSECA et al., 2016; FRANGOUDES e GERRARD, 2018; GUSTAVSSON e RILEY, 2018; SOUZA et al., 2019).

Além dos estudos envolvendo questões de gênero, pesquisas no campo da Etnobotânica têm abordado o conhecimento e o uso das plantas na pesca tradicional (BEGOSSI et al., 1993; HANAZAKI et al., 2000; BEGOSSI et al., 2002; FONSECAKRUEL e PEIXOTO, 2004; MIRANDA e HANAZAKI, 2008; BORGES e PEIXOTO, 2009; MERÉTIKA et al., 2010; BRITO e SENNA-VALLE, 2012; LOPES e LOBÃO, 2013; OROFINO et al., 2017). Estudos nessa área fortalecem o protagonismo feminino e sua autonomia no setor pesqueiro ao destacarem, registrarem e valorizarem seus conhecimentos (MARTINEZ e HELLEBRANT, 2019; SOUZA et al., 2019), além de se alinharem aos Objetivos de Desenvolvimento Sustentável (ODS) na garantia da segurança alimentar (ODS2), no empoderamento feminino, na equidade de gênero (ODS5) e na conservação e uso sustentável dos recursos marinhos (ODS14) (ONU, 2015).

Nesse contexto, partimos do pressuposto de que as mulheres desempenham papel fundamental na segurança alimentar e na atividade pesqueira, detendo saberes sobre os recursos naturais costeiros (plantas da restinga e pescados). Com isso, este estudo teve como objetivos investigar os conhecimentos sobre a flora da restinga, assim como caracterizar as atividades pesqueiras exercidas pelas mulheres em Arraial do Cabo, uma das comunidades mais antigas de pesca do litoral do Rio de Janeiro. Buscou-se, ainda, comparar a atuação feminina durante os anos de 1940-1960 com a da mulher após esse período até os dias atuais, pois essas três décadas marcam uma transição de modos de vida pré-industriais para pós-industriais em diversas comunidades de pesca artesanal no Brasil, refletindo no papel feminino (WOORTMANN, 1992). Esperamos com essa análise contribuir para a valorização das mulheres que trabalham na pesca em Arraial do Cabo, bem como de seus conhecimentos associados, de modo a promover maior visibilidade e equidade de gênero (FAO, 2016; FAO, 2020). 
LUIJK, N. et al. Mulheres e a pesca artesanal: salvaguardando conhecimentos tradicionais sobre plantas da restinga em Arraial do Cabo, Brasil. Ethnoscientia v.6 n. 2, especial, 2021. DOI: 10.22276/ethnoscientia.v6i2.388

\section{MATERIAL E MÉTODO}

A pesquisa foi realizada em Arraial do Cabo (22 $57^{\prime} 58^{\prime \prime}$ e $\left.42^{\circ} 01^{\prime} 40^{\prime \prime}\right)$, em uma das comunidades mais antigas de pesca artesanal costeira no estado do Rio de Janeiro, que dista aproximadamente $140 \mathrm{~km}$ da capital (BRITTO, 1999; IBGE, 2017). Antigos relatos já evidenciavam a pesca nessa área, como a praticada pelos indígenas do Brasil pré-colonial e, posteriormente com a colonização, pelos portugueses após o século XVII, quando a atividade se estabeleceu como base econômica local, tornando a região uma pequena vila de pescadores artesanais (BERNARDES e BERNARDES, 1950; BRITTO, 1999). Deste modo, os habitantes de Arraial do Cabo viviam do extrativismo de pescados e plantas a partir do mar e da restinga como únicas fontes de recursos (BRITTO, 1999; PRADO, 2002), especialmente devido à posição de promontório (uma ponta de terra que se estende para o oceano) (COE et al., 2007). Essa característica geográfica limitou, por anos a fio, o acesso à região por terra, de maneira que a população vivia em relativo isolamento (BRITTO, 1999; PRADO, 2002). Logo, Arraial do Cabo se manteve como pequeno núcleo pesqueiro e distrito do município de Cabo Frio até 1985, quando foi emancipado (IBGE, 1959; Rio de Janeiro, 1985). Atualmente, há cerca de 27.715 moradores ocupando 158,952 $\mathrm{km}^{2}$, cujas principais atividades econômicas seguem na base da pesca e do turismo sazonal (IBGE, 2010).

O clima local é semiárido, com baixa precipitação (menos de $900 \mathrm{~mm}$ anuais), temperatura média de $24^{\circ} \mathrm{C}$ e fortes ventos do quadrante norte-nordeste (ARAUJO et al.,1997; COE et al., 2007). Nessa área há ocorrência do importante fenômeno da ressurgência, que resulta em abundância populacional de peixes, crustáceos e moluscos (COE et al., 2007). Em termos de ambientes, há predomínio das restingas, planícies arenosas costeiras com mosaicos de vegetação, associadas ao bioma mata atlântica (CONAMA, 2009; BRASIL, 2012; MARQUES et al., 2015). Essas características geográficas e ecológicas propiciam a pesca, sendo ainda uma das fontes de subsistência para a comunidade de Arraial do Cabo. Inclusive, há grupos de mulheres atuando na atividade pesqueira e que são detentoras de conhecimentos relacionados tanto à fauna marinha quanto à flora costeira, como as restingas (FONSECA-KRUEL e PEIXOTO, 2004; RIBEIRO e NASCIMENTO, 2020).

\subsection{Coleta e análise de dados}

Foram realizadas visitas informais à Prainha, Centro e Praia Grande, localidades em Arraial do Cabo, onde há pesca artesanal com envolvimento de mulheres que pertencem aos 
LUIJK, N. et al. Mulheres e a pesca artesanal: salvaguardando conhecimentos tradicionais sobre plantas da restinga em Arraial do Cabo, Brasil. Ethnoscientia v.6 n. 2, especial, 2021. DOI: 10.22276/ethnoscientia.v6i2.388

núcleos familiares nativos e tradicionais, chamadas de cabistas. Nessas visitas, encontramos antigas salgadeiras de peixe e outras que trabalham com pescado e fazem parte de organizações locais, como a Cooperativa de Mulheres Nativas de Arraial do Cabo. A partir dessas conversas informais, foram indicadas duas cabistas especialistas em restinga.

Entrevistas semiestruturadas foram realizadas junto a essas duas parceiras, sendo uma delas filha, neta, irmã e sobrinha de pescadores, nascida em 1955 e integrante da Cooperativa de Mulheres Nativas, na Praia Grande. A outra colaboradora foi uma antiga salgadeira, filha e irmã de pescadores, nascida em 1936, residente no Centro e aposentada atualmente. A entrevista com a salgadeira ocorreu em sua residência em maio de 2017 e com a cooperada por videoconferência pelo aplicativo Whatsapp, em maio de 2020, em razão da pandemia da COVID-19. Ressalta-se que devido à situação pandêmica e à interrupção das atividades, para o devido cumprimento do distanciamento social, não foi possível encontrar outras cooperadas para colaborar com esta pesquisa. Além disso, foi uma escolha metodológica trabalhar apenas com cabistas especialistas em restinga. As principais questões abordadas foram: (1) qual a atuação da mulher na cadeia produtiva da pesca praticada em Arraial do Cabo antes de 1960 e atualmente? e (2) quais os conhecimentos salvaguardados pelas mulheres sobre a pesca e sobre os usos das plantas da restinga?

Informações complementares, sobre o modo de vida das famílias na comunidade de pesca artesanal e o uso de plantas da restinga por homens e mulheres, foram obtidas a partir de narrativas feitas em oficinas de trocas de saberes entre membros da comunidade, realizadas em setembro de 2019, na Cooperativa de Mulheres Nativas e no Instituto Federal de Educação, Ciência e Tecnologia do Rio de Janeiro, campus Arraial do Cabo (IFRJ). As bases de dados SciELO e Google Acadêmico foram consultadas para realização de revisão bibliográfica em livros, artigos, dissertações e teses relacionadas à atividade pesqueira no município em estudo, assim como às transformações socioculturais a partir da segunda metade do século XX, para uma melhor compreensão do papel feminino na pesca local. A técnica de análise de conteúdo (MORAES, 1999) foi utilizada para eleger bibliografias que abordassem as atividades desempenhadas por mulheres, como confecção e reparo de apetrechos de pesca, captura e beneficiamento do pescado e/ou aquelas relacionadas ao uso de plantas da restinga. Tais publicações foram analisadas concomitantemente às entrevistas, buscando uma relação temporal de acontecimentos e/ou transformações socioeconômicas e/ou culturais locais.

Ressaltamos que foram seguidos os aspectos éticos e as orientações do Código de Ética da Sociedade Internacional de Etnobiologia (ISE, 2006). Logo, as colaboradoras 
LUIJK, N. et al. Mulheres e a pesca artesanal: salvaguardando conhecimentos tradicionais sobre plantas da restinga em Arraial do Cabo, Brasil. Ethnoscientia v.6 n. 2, especial, 2021. DOI: 10.22276/ethnoscientia.v6i2.388

foram informadas dos objetivos e consentiram no desenvolvimento da pesquisa. Não foram realizadas coletas de material biológico. A Resolução No 510/2016 do Ministério da Saúde também foi seguida.

\section{RESULTADOS E DISCUSSÃO}

\subsection{Atuação da mulher na cadeia produtiva da pesca praticada em Arraial do Cabo antes de 1960}

Foram consultadas, a partir da revisão bibliográfica, onze publicações científicas sobre a pesca artesanal que abrangem o papel da mulher na cadeia produtiva. Baseando-se nas análises das entrevistas realizadas e nos estudos feitos por Bernardes e Bernardes (1950), Fontenelle (1960), Britto (1999), Prado (2002) e Brettas (2018), observou-se que a segunda metade do século XX foi marcada por profundas mudanças no modo de vida em Arraial do Cabo. Tais alterações refletiram diretamente na atuação feminina na pesca, principalmente entre 1930 e 1940, com a criação das estradas que conectaram o distrito de Arraial do Cabo a Cabo Frio e diminuíram o isolamento geográfico facilitando o escoamento do pescado (FONTENELLE, 1960; PRADO, 2002). Na década de 1950, a inauguração e funcionamento da Companhia Nacional de Álcalis (CNA), uma indústria de sal e barrilha, gerou mudanças socioeconômicas representativas. A CNA causou grande aumento populacional devido ao aporte imigratório de outros estados e municípios, fomentou a ampliação da infraestrutura urbana, a captação e distribuição de água e a criação de estabelecimentos comerciais, escolas e unidades de saúde (FONTENELLE, 1960; BRITTO, 1999). Outro grande marco foi a inauguração da Ponte Rio-Niterói, na década de 1970, que facilitou o acesso à região metropolitana e ao interior do estado do Rio de Janeiro, bem como causou o contínuo aumento do turismo de massa, da imigração e da especulação imobiliária (IBGE, 2017).

Até 1960 a identidade cultural local era ligada ao mar, onde todos na comunidade apresentavam alguma relação com a pesca e com a flora da restinga. $\mathrm{O}$ processo de industrialização gerou gradativas transformações sociais, culturais e econômicas que afetaram também o papel da mulher dentro da pesca artesanal e sua relação com a biodiversidade, como salientado em entrevista com a especialista local:

A questão da pescaria, para mim, não é nem de quando começou: é questão de vida. Todos os homens da minha família, quando eu nasci, estavam na pescaria: meus avós, pais, irmãos, minha mãe como salgadeira. Meus tios por parte da minha mãe, os maridos das minhas tias... Estavam todos envolvidos na pesca. A pescaria já estava na nossa vida naquela época [década de 1950]. Mas o 
LUIJK, N. et al. Mulheres e a pesca artesanal: salvaguardando conhecimentos tradicionais sobre plantas da restinga em Arraial do Cabo, Brasil. Ethnoscientia v.6 n. 2, especial, 2021. DOI: 10.22276/ethnoscientia.v6i2.388

machismo naquela época era muito intenso. Nenhuma de nós [mulheres] podia estar na pescaria efetivamente (Mulher cabista da Praia Grande, informação oral, 30 de maio de 2020).

Desse modo, a pesca e a salga de peixe constituíam as bases econômicas locais e regiam o modo de vida dos habitantes dessa comunidade. As atividades cotidianas eram distintas e segregadas por gênero: as responsabilidades masculinas eram o provimento financeiro e alimentar da família, enquanto as responsabilidades femininas eram os cuidados domésticos e a criação dos filhos (FONTENELLE, 1960), valores culturais comuns nas organizações sociais de comunidades pesqueiras (WOORTMANN, 1992). Nesse cenário, as mulheres em Arraial do Cabo trabalhavam mais que os homens, pois, além dos cuidados mencionados, as especialistas mencionaram nas entrevistas que atuavam no beneficiamento pesqueiro, na captação de água doce em cacimbas cavadas nas areias da restinga, na colheita de lenha a partir da vegetação de restinga, na fiação e tecelagem de redes de pesca, na produção de renda de bilros ${ }^{1}$ e costura como fontes de renda, bem como na lavagem de roupas como serviço para terceiros. Esse papel multifacetado e a responsabilidade de coordenar diversas atividades têm sido um padrão frequente em comunidades de pesca e herdado culturalmente (FONTENELLE, 1960; WOORTMANN, 1992; FONSECA et al., 2016; MENDES e PARENTE, 2016; GUSTAVSSON e RILEY, 2018).

O setor de beneficiamento do pescado era predominantemente ocupado pelas mulheres que limpavam e conservavam o peixe - utilizando o sal, recurso abundante em Arraial do Cabo - para os donos dos paióis de salga. A salga também foi observada por Woortmann (1992), no Nordeste brasileiro, como atividade essencialmente feminina. Em Arraial do Cabo, as mulheres não participavam da captura direta do peixe, mas eventualmente pescavam lula de linha no costão rochoso. Todavia, essa atividade era considerada lazer e ocorria de forma discreta, não sendo legitimada como pesca. A pesca legítima, nos valores de Arraial do Cabo, é aquela realizada em canoas de borçada, embarcações feitas de tronco único com adição de tábuas nas bordas (BARRETO et al., 2019), nas quais o pescador é aquele que pratica a "pescaria", e depende dela para subsistência e reprodução cultural. A pescaria tradicional é uma modalidade feita por homens, em embarcações a remo, com uso de redes de cerco, da qual mulheres não participam.

\footnotetext{
${ }^{1}$ Atividade feminina, de origem portuguesa, na qual a renda é feita manualmente sobre uma almofada,

2 Termo local para se referir a pesca artesanal em canoas de borçada (BARRETO et al., 2019).
} 
LUIJK, N. et al. Mulheres e a pesca artesanal: salvaguardando conhecimentos tradicionais sobre plantas da restinga em Arraial do Cabo, Brasil. Ethnoscientia v.6 n. 2, especial, 2021. DOI: 10.22276/ethnoscientia.v6i2.388

De acordo com as entrevistas realizadas, as especialistas informaram que as mulheres não apresentavam habilidades técnicas e especificas relativas à pescaria tradicional e que os conhecimentos foram adquiridos pela vivência na comunidade, principalmente através das relações familiares. Resultados similares foram encontrados por Mendes e Parente (2016) e Gustvasson e Riley (2018). Segundo esses pesquisadores, as mulheres entraram no universo da pesca através de aprendizados adquiridos com seus pais e companheiros. Essa descoberta ressalta a importância das relações e da organização social nas comunidades de pesca artesanal (WOORTMANN, 1992).

Segundo as entrevistas e os registros de Prado (2002), Britto (1999) e Brettas (2017), a atuação feminina na cadeia produtiva da pesca artesanal era o único método disponível de conservação do pescado, através da salga do peixe para os donos dos paióis, atividade insalubre, desconfortável e que exigia muito do corpo. Elas aprendiam a salgar por meio da observação e prática junto às outras mulheres: mães, tias, avós e vizinhas. O processo correspondia às seguintes etapas: escalar, lavar, salgar, empilhar, ressalgar e embalar para transporte, sendo todas realizadas por mulheres (BRITTO, 1999). Contudo, é importante ressaltar que, ainda assim, a salga era considerada uma função auxiliar e subalterna, uma renda complementar à do marido ou à do pai, apesar de fundamental dentro da cadeia produtiva local.

Conforme as entrevistas com as especialistas, as mulheres iniciavam o beneficiamento na praia, com a limpeza do peixe fresco, que era então transportado para os paióis, onde ocorria a salga. As salgadeiras ficavam de cócoras no chão, com a pilha de sal de um lado e a de peixe fresco do outro. O pescado era revestido com sal grosso nas partes interna/externa e logo depois empilhado em um tanque para permanecer em repouso entre 5 e 30 dias antes da retirada da salmoura. Em seguida, o produto era recoberto de sal fino e posto para secar em redes sob o sol, nos paióis de salga ou nos telhados de casa quando para consumo próprio. Após a secagem total, era embalado em cestos para transporte (BRITTO, 1999; BRETTAS, 2017).

A salga foi gradativamente sendo extinta com a disponibilidade do gelo, a partir da década de 1950, de modo que já não era praticada por mulheres nascidas depois de 1960 . Outros fatores mencionados que contribuíram para mudanças no papel da mulher na pesca foram a oferta de novos empregos e o casamento entre pessoas das famílias nativas com imigrantes, o que gerou um novo perfil familiar local, padrão similar em outras áreas do Brasil (WOORTMANN, 1992). 
LUIJK, N. et al. Mulheres e a pesca artesanal: salvaguardando conhecimentos tradicionais sobre plantas da restinga em Arraial do Cabo, Brasil. Ethnoscientia v.6 n. 2, especial, 2021. DOI: 10.22276/ethnoscientia.v6i2.388

\subsection{Atuação da mulher na cadeia produtiva da pesca atual praticada em Arraial do Cabo}

Apesar da atual extinção do ofício de salgadeira, as mulheres em Arraial do Cabo continuaram a ocupar o espaço da pesca, gradualmente se inserindo na captura do pescado, gerando maior autonomia, principalmente a partir dos anos 2000, como mostram os estudos de Souza et al. (2012), Marendino e Carvalho (2013), Ferreira (2016), (2017), (2020) e Ribeiro e Nascimento (2020). Contudo, ainda prevalece a percepção cultural das atribuições de gênero, na qual a mulher é auxiliar nas atividades pesqueiras, fato marcante em Arraial do Cabo assim como em diversas comunidades pesqueiras no Brasil e no mundo (WOORTMANN, 1992; BRITTO, 1999; HARPER et al., 2013; MENDES e PARENTE, 2016; FONSECA et al, 2016; GUSTAVSSON e RILEY, 2018).

As entrevistas realizadas com as especialistas locais demonstraram que o processo de inserção profissional da mulher, no setor da captura do pescado mar adentro, foi favorecido pela chegada de modernas tecnologias, como embarcações a motor e anzóis. É importante salientar que aquelas que pescam em Arraial do Cabo não se autodeterminam pescadoras tradicionais, distinguindo sua pescaria daquela realizada pelos homens (nas canoas de borçada) e das outras modalidades de pesca tradicional. Para elas, trata-se de lazer e atividade suplementar às suas outras atuações profíssionais, uma vez que não dependem dela para subsistência, sendo, portanto, a pesca de mulher distinta da pesca tradicional. Complementando essas informações, Ribeiro e Nascimento (2020) reportam que as envolvidas na pesca em Arraial do Cabo se identificam como mulheres da pesca em vez de pescadoras.

É interessante ressaltar que, no entanto, um avanço vem sendo observado na região com o reconhecimento da presença feminina na pesca local, especialmente a partir do estabelecimento da Cooperativa de Mulheres Nativas de Arraial do Cabo, criada em 2013 na Praia Grande e composta exclusivamente por cerca de 23 mulheres $^{3}$, com idades entre 57 e 75 anos. A renda obtida é complementar ao orçamento familiar, pois a maioria exerce outras profissões. As atividades por elas desempenhadas vão desde a captura do pescado (lula, olho de cão e peroá) - através da pesca por linha em embarcações a motor ${ }^{4}$-, beneficiamento deste, até a produção e venda de mercadorias, envolvendo todos os setores da cadeia produtiva. Na cooperativa, vêm sendo elaborados diversos produtos cuja matériaprima é o peixe (quibes, hambúrgueres, nuggets, sorvetes e bolos), comercializados na sede

3 Existe em Arraial do Cabo a Cooperativa das Mulheres Pescadoras, Aquicultoras e Artesãs da Prainha - Sol, Salga e Arte (MUPAART), composta por $70 \%$ de mulheres e por $30 \%$ de homens.

$4 \mathrm{O}$ barco e a condução são serviços terceirizados. 
LUIJK, N. et al. Mulheres e a pesca artesanal: salvaguardando conhecimentos tradicionais sobre plantas da restinga em Arraial do Cabo, Brasil. Ethnoscientia v.6 n. 2, especial, 2021. DOI: 10.22276/ethnoscientia.v6i2.388

e em festas na cidade. As cooperadas utilizam receitas familiares e tradicionais, como o peixe salgado com banana e agregam, por vezes, ingredientes da restinga (como os frutos da aroeira e algumas espécies pertencentes à família Myrtaceae). Desse modo, a cooperativa vem reforçando o papel da mulher de forma inovadora na pesca local, no meio científico e na gastronomia da região, através da diversificação mencionada de produtos feitos à base de peixe e plantas da restinga. Essas ações visam tanto à geração de renda local como inspirar os jovens na perspectiva de geração de emprego, perpetuando a identidade pesqueira. Além disso, a cooperativa tem aumentado o engajamento político feminino, através de parcerias com instituições representativas - como a Colônia de Pescadores, a FIPERJ, a Fundação Instituto de Pesca de Arraial do Cabo e a Reserva Extrativista Marinha de Arraial do Cabo.

A exemplo de Arraial do Cabo, esse tipo de organização social em cooperativas de mulheres vem se repetindo em algumas partes do litoral brasileiro. Tal fato demonstra o maior reconhecimento da multiplicidade de papéis desempenhados por elas e suas contribuições para o setor de pesca. Em contraponto, a FAO (2016) destacou que ainda existem poucas trabalhadoras em organizações de pescadores em todo o mundo, sendo rara a presença delas nas posições de tomada de decisão (ALONSO-POBLACIÓN e SIAR, 2018; FAO, 2020).

\subsection{Conhecimentos salvaguardados pelas mulheres sobre a pesca e os usos das plantas da restinga}

A pesca tradicional em Arraial do Cabo demonstra forte associação ao uso de plantas da restinga, sendo estas uma fonte de recursos para confecção de apetrechos, remendos e bordaduras para as canoas de borçada (FONTENELLE, 1960; BRITTO, 1991; PRADO, 2002; BARRETO et al, 2019). As entrevistas com as especialistas salientaram que as mulheres apresentavam conhecimentos sobre a técnica de manufatura de agulhas de pesca a partir de galhos da Eugenia uniflora (pitanga), o manuseio do fuso para fiação de linhas feitas a partir do fio da folha de Bactris setosa (tucum), o esmagamento das raízes de Byrsonima sericea (murici) para a tintura de redes de pesca, além da própria tecelagem delas, atividades estas realizadas em domicílio. No entanto, a confecção da rede era realizada majoritariamente pelos homens (BRITTO, 1999), apesar de frequentemente as esposas e filhas auxiliarem no processo de confecção e reparo de redes menores, as “tarrafas" (BERNARDES e BERNARDES, 1950). Nos dias atuais a flora da restinga não é 
LUIJK, N. et al. Mulheres e a pesca artesanal: salvaguardando conhecimentos tradicionais sobre plantas da restinga em Arraial do Cabo, Brasil. Ethnoscientia v.6 n. 2, especial, 2021. DOI: 10.22276/ethnoscientia.v6i2.388

utilizada para produção desses utensílios, principalmente devido à disponibilidade de apetrechos industrializados, introduzidos gradualmente entre o período de 1970 a 1990.

Além do uso de plantas na pesca, a colheita de frutos da restinga como complemento da dieta familiar, consumidos in natura durante caminhadas e/ou a cavalo em família, era uma prática frequente em Arraial do Cabo durante o século XX (PRADO, 2002; FONSECA-KRUEL \& PEIXOTO, 2004). O costume provavelmente foi herdado dos povos indígenas Tupinambás durante a miscigenação com os colonizadores portugueses entre os séculos XVI e XIX (PRADO, 2002).

Segundo as entrevistas, essas expedições ocorriam durante os períodos de frutificação, usualmente na primavera/verão (entre fevereiro e abril), podendo durar um dia inteiro. $\mathrm{O}$ volume de frutos disponíveis na vegetação era o principal motivo das saídas. A oferta era sazonal, especialmente para os considerados mais saborosos. Os mais apreciados eram das espécies Myrciaria floribunda (cambuí), Pouteria caimito (guapeba), Garcinia brasiliensis (bacupari), Eugenia pruniformis (azeitona), Inga laurina (ingá), Eugenia uniflora (pitanga) e Eugenia selloi (pintagobaia). Contudo, outras espécies, apesar de consideradas menos apetitosas, apresentavam maior disponibilidade na restinga, como Eugenia copacabanensis (bapuana) e Byrsonima sericea (murici).

Outros estudos também apontaram o potencial nutricional e a utilização dos frutos da restinga em comunidades de pesca artesanal no litoral Sudeste (BEGOSSI et al., 1993; BEGOSSI et al., 2002; MIRANDA e HANAZAKI, 2008; BORGES e PEIXOTO, 2009; BRITO e SENNA-VALLE, 2012). Apesar dos resultados evidenciarem a importância dos frutos como complemento da dieta local baseada no pescado, a colheita vem diminuindo gradativamente desde os anos 2000, segundo as entrevistas, como consequência da supressão da vegetação por ações antrópicas e do aumento da violência nas áreas de restinga.

\section{CONSIDERAÇÕES FINAIS}

A inclusão das mulheres na cadeia produtiva da pesca é um dos desafios salientados em diversas publicações. Trata-se ainda de uma área que enfrenta dificuldades para criar oportunidades a elas, para que participem e se beneficiem do setor de pesca de pequena escala de maneira equitativa, buscando transformá-lo e contribuindo para o empoderamento e eliminação da discriminação. As atribuições femininas na pesca em Arraial do Cabo, na forma de beneficiamento através da salga, ainda que subestimadas e exploradas no passado pelos donos de paióis, foram fundamentais para a cadeia produtiva, segurança alimentar e 
LUIJK, N. et al. Mulheres e a pesca artesanal: salvaguardando conhecimentos tradicionais sobre plantas da restinga em Arraial do Cabo, Brasil. Ethnoscientia v.6 n. 2, especial, 2021. DOI: 10.22276/ethnoscientia.v6i2.388

identidade da comunidade. O registro e a valorização do trabalho que as mulheres desempenharam (e ainda desempenham) na pesca é o passo inicial para o fortalecimento de sua autoestima e autonomia, assim como para seu devido reconhecimento por parte das instituições oficiais. Nesse sentido, observou-se um avanço na comunidade em Arraial do Cabo, na qual as trabalhadoras da pesca, apesar de não praticarem a pesca artesanal dos homens, vêm somando esforços na forma de cooperativas e ocupando espaços antes negados, inclusive de forma inovadora ao contribuírem para a geração e movimentação de capital na região. Por fim, os conhecimentos sobre as plantas de restinga, especialmente as alimentícias, mostraram-se relevantes tanto na segurança alimentar, quanto na perpetuação do conhecimento tradicional relacionado à identidade pesqueira da comunidade. Por todo o exposto, é possível concluir que as mulheres são importantes detentoras e transmissoras de saberes que integram o patrimônio cultural imaterial da região.

\section{AGRADECIMENTOS}

Agradecemos a todas as mulheres e homens cabistas que contribuíram de forma direta e indireta para este trabalho e ao sociólogo Paulo Sérgio Barreto pelas ricas revisões e sugestões.

\section{REFERÊNCIAS BIBLIOGRÁFICAS}

ALONSO-POBLACIÓN, E; SIAR, S.V. Women's participation and leadership in fisherfolk organizations and collective action in fisheries: a review of evidence on enablers, drivers and barriers. FAO Fisheries and Aquaculture Circular, Rome, v.1. n. 1159, p.11-37, 2018.

ARAUJO, D. S. D. The Cabo Frio Region. In: DAVIS, S. D.; HEYWOOD, V. H.; HERRERAMACBRYDE, O.; VILLA-LOBOS, J.; HAMILTON, A. C. (eds.). Centres of plant diversity: a guide and strategy for their conservation. Oxford: WWF/IUCN, 1997, p.373-375.

ARAUJO, D. S. D. Análise florística e fitogeográfica das restingas do estado do Rio de Janeiro. 2000. 176f. Tese (Doutorado em Ecologia). Instituto de Biologia, Universidade Federal do Rio de Janeiro, Rio de Janeiro.

BARRETO, P.S.; ANDRADE, C.A.; SILVA, W.L.; SILVA, A.; FONSECA-KRUEL, V.S. As canoas de borçada em Arraial do Cabo.. In: MELO-JÚNIOR, J.C.F.; FONSECA-KRUEL, V.S.; HANAZAKI, N.(org.). Árvores e madeiras na cultura naval tradicional. Joinvile: Ed. Univille, 2019, cap. 1, p.17-50.

BEGOSSI, A.; LEITÃO-FILHO, H.E.; RICHERSON, P.I. Plant uses in a brazilian coastal fishing community (Buzios Island). Journal of Ethnobiology. v.13. n. 2. p.233-256, 1993. 
LUIJK, N. et al. Mulheres e a pesca artesanal: salvaguardando conhecimentos tradicionais sobre plantas da restinga em Arraial do Cabo, Brasil. Ethnoscientia v.6 n. 2, especial, 2021. DOI: 10.22276/ethnoscientia.v6i2.388

BEGOSSI, A.; HANAZAKI, N.; TAMASHIRO, J.Y. Medicinal plants in the Atlantic Forest (Brazil): knowledge, use and conservation. Human Ecology, v30, n. 3, p.281-299, 2002.

BERNARDES, L.M.C; BERNARDES, N. A pesca no litoral do Rio de Janeiro. Revista Brasileira de Geografia, Rio de Janeiro, v.12. n.1, p.17-54, 1950.

BRASIL. 2012. Lei $\mathbf{n}^{\mathbf{0}} \mathbf{1 2 . 6 5 1}$, de 25 de maio de 2012. Dispõe sobre a proteção da vegetação nativa; altera as Leis $\mathrm{n}^{\circ}$ s 6.938, de 31 de agosto de 1981, 9.393, de 19 de dezembro de 1996, e 11.428, de 22 de dezembro de 2006; revoga as Leis $\mathrm{n}^{\circ} \mathrm{s}$ 4.771, de 15 de setembro de 1965, e 7.754, de 14 de abril de 1989, e a Medida Provisória n ${ }^{\circ}$ 2.166-67, de 24 de agosto de 2001; e dá outras providências.

BRASIL. Ministério da Saúde. Conselho Nacional de Saúde. 2016. Resolução No 510 de 7 de abril de 2016. Dispõe sobre as normas aplicáveis a pesquisas em Ciências Humanas e Sociais cujos procedimentos metodológicos envolvam a utilização de dados diretamente obtidos com os participantes ou de informações identificáveis ou que possam acarretar riscos maiores do que os existentes na vida cotidiana, na forma definida nesta Resolução.

BRETTAS, L.F.M. Do mar à mesa: a pesca e a alimentação em Arraial do Cabo entre as décadas de 1930 e 1960. 2018. 161 f. Dissertação. (Mestrado Profissional em Bens Culturais e Projetos Sociais) - Centro de Pesquisa e Documentação de História Contemporânea do Brasil, Fundação Getúlio Vargas, Rio de Janeiro.

BRITO, M.R.; SENNA-VALLE, L. Diversity of plant knowledge in a 'Caiçara' community from the Brazilian Atlântic Florest coast. Acta Botanica Brasilica, Feira de Santana, v.26. n.4. p.735$747,2012$.

BRITO, C.I. Uma análise sócio-histórica da Articulação Nacional das Pescadoras (ANP). In: MARTÍNEZ, S.A.; HELLEBRANT, L. (orgs). Mulheres na atividade pesqueira no Brasil. Campos dos Goytacazes: EDUENF, 2019, p.51-74.

BRITTO, R. C. Modernidade e tradição - construção da identidade social dos pescadores de Arraial do Cabo. Niterói: Eduff, 1999, Niterói, 265p.

COE, H. H. G.; CARVAlHO, C. N.; SOUZA L. O. F.; SOARES, A. 2007. Peculiaridades Ecológicas da Região de Cabo Frio, RJ. Revista de Tamoios UERJ, Rio de Janeiro, v.4, n 2, p.120, 2007.

CONAMA. 2009. Resolução n $^{\mathbf{4}} 417$ de 23 de novembro de 2009. Dispõe sobre parâmetros básicos para definição de vegetação primária e dos estágios sucessionais secundários da vegetação de Restinga na Mata Atlântica e dá outras providências.

CRUZ, A.V.M; KAPLAN, M.A.C. Uso medicinal de espécies das famílias myrtaceae e melastomataceae no Brasil. Floresta e Ambiente, Seropédica, v. 11. n.1. p. 47-52, 2004.

FAO. Promoting gender equality and women's empowerment in fisheries and aquaculture. Roma, p.1-12, 2016. Disponível em: http://www.fao.org/3/a-i6623e.pdf Acesso em 19 jun. 2020. 
LUIJK, N. et al. Mulheres e a pesca artesanal: salvaguardando conhecimentos tradicionais sobre plantas da restinga em Arraial do Cabo, Brasil. Ethnoscientia v.6 n. 2, especial, 2021. DOI: 10.22276/ethnoscientia.v6i2.388

FAO. The State of World Fisheries and Aquaculture 2020. Sustainability in action. Roma. v.1.n1.p.1-76, 2020. Disponível em https://doi.org/10.4060/ca9229en_Acesso em 19 jun. 2020.

FERREIRA, M.A. Entre redes de discursos e de pesca - performances narrativas de mulheres pescadoras em Arraial do Cabo. 2016. 199 f. Tese. (Doutorado em Linguística Aplicada) UFRJ, Rio de Janeiro.

FERREIRA, M.A.“Eles num vê uma mulhé na água / (...) eles vê como se fosse um homem": cronótopos e performances de gênero na pesca em Arraial do Cabo. Caderno Espaço Feminino, Uberlândia, v. 30, n. 1, p.279-303, 2017.

FERREIRA, M.A. Nós não somos feministas. Só queremos ser reconhecidas como Pescadoras: interseccionalidades e performances narrativas de pescadoras negras em Arraial do Cabo. Linguagem em Foco, Fortaleza, v.11, n.2, p. 148-164, 2020.

FONSECA, M.; ALVES, F.; MACEDO, M. C.; AZEITEIRO, U. M. O Papel das Mulheres na Pesca Artesanal Marinha: Estudo de uma Comunidade Pesqueira no Município de Rio das Ostras, RJ, Brasil. Journal of Integrated Coastal Zone Management. Lisboa, v.16.n.2.p.231-241, 2016.

FONSECA-KRUEL, V.S, PEIXOTO, A.L. Etnobotânica na Reserva Extrativista Marinha de Arraial do Cabo, RJ, Brasil. Acta Botanica Brasilica. Feira de Santana, v.18 n.1, p.177-190, 2004.

FONTENELLE, L.F.R. A dinâmica dos grupos domésticos no Arraial do Cabo. Rio de Janeiro: Serviço Social Rural Edições, 1960, 42p.

FRANGOUDES, K.; KEROMNES, E. 2008. Women in artisanal fisheries in Brittany, France. Development Palgrave Macmillan Society for International Deveopment, Londres, v. 51.n.2, p.265-270, 2008.

FRANGOUDES, K., GERRARD, S. (En)Gendering Change in Small-Scale Fisheries and Fishing Communities in a Globalized World. Maritime Studies, Califórnia, n.17. p.117-124, 2018.

GUSTAVSSON, M.; RILEY, M. Women, capitals and fishing lives: exploring gendered dynamics in the Llŷn Peninsula small-scale fishery (Wales, UK). Maritime Studies Califórina, n.17. p.223$231,2018$.

HANAZAKI, N., TAMASHIRO, J.Y., LEITÃO-FILHO, H.F. Diversity of plant uses in two Caiçara communities from the Atlantic Forest coast, Brazil. Biodiversity and Conservation, Londres, n.9, p.597-615, 2000.

HARPER, S.; ZELLER, D.; HAUZER, M.; PAULY, D.; SUMAILA, R.U. Women and fisheries: Contribution to food security and local economies. Marine Policy Amsterdã, n.39. p.56-63, 2013.

IBGE. Cabo Frio. In: Enciclopédia dos municípios brasileiros. Rio de Janeiro: IBGE Publicações, v. 22, 1959, p. 210-216. Disponível em:

$<$ http://biblioteca.ibge.gov.br/visualizacao/livros/liv27295_22.pdf $>$ Acesso em 25 mar. 2020. 
LUIJK, N. et al. Mulheres e a pesca artesanal: salvaguardando conhecimentos tradicionais sobre plantas da restinga em Arraial do Cabo, Brasil. Ethnoscientia v.6 n. 2, especial, 2021. DOI: 10.22276/ethnoscientia.v6i2.388

IBGE. Censo 2010. Arraial do Cabo. 2010. Disponível em

$<$ http://cidades.ibge.gov.br/xtras/temas.php?lang=ecodmun=330025eidtema=1 esearch=rio-dejaneiro|arraial-do-cabo|censo-demografico-2010:-sinopse- > Acesso em 22 jul. 2017.

IBGE. Cidades v4.4.11, 2017. Arraial do Cabo. Disponível em $<$ https://cidades.ibge.gov.br/brasil/rj/arraial-do-cabo/panorama> Acesso em 30 out. 2020.

ISE, International Society of Ethnobiology. Código de Ética da ISE (com adições em 2008). 2006. Disponível em: $<$ http://www.ethnobiology.net/ethics.php $\geq$ Acesso em 20 fev. 2020.

LINSKER, R.; TASSARA, H. O mar é uma outra terra. São Paulo: Terra Virgem, 2005, 96p.

LOPES, L.C.M; LOBÃO, A.Q. Etnobotânica em uma comunidade de pescadores artesanais no litoral norte do Espírito Santo, Brasil. Boletim do Museu de Biologia Mello Leitão, Santa Teresa, n.32. p.29-52, 2013.

MARENDINO, R.B.; CARVALHO, J.G. Mulheres pescadoras de Arraial do Cabo: imaginário, representações e gênero. Emblemass, Catalão, v. 10, n. 2, p.59-76, 2013.

MARQUES, M.C.M.; SILVA, S.M.; LIEBSCH, D. Coastal plain forests in southern and southeastern Brazil: ecological drivers, floristic patterns and conservation status. Brazilian Journal of Botany, v.38 n.1. p.1-18, 2015.

MARTÍNEZ, S.A.; HELLEBRANT, L. Mulheres na atividade pesqueira no Brasil: uma introdução. In: MARTÍNEZ, S.A.; HELLEBRANT, L. (orgs). Mulheres na atividade pesqueira no Brasil. Campos dos Goytacazes: EDUENF, 2019, p.09-20.

MENDES, SHAMA; PARENTE, TGPC. (In)visibilidade das mulheres na pesca artesanal: uma análise sobre as questões de gênero em Miracema do Tocantins - TO. Revista Brasileira de Desenvolvimento Regional, Blumenau, v.4. n.2, p.177-199, 2016.

MERÉTIKA, A.H.C., PERONI, N.; E HANAZAKI, N. Conhecimento local de plantas medicinais em três comunidades pesqueiras artesanais (Itapoá, Sul do Brasil), de acordo com gênero, idade e urbanização. Acta Botanica Brasilica, Feira de Santana, v.24. n.2. p.386-394, 2010.

MORAES, R. Análise de conteúdo. Revista Educação, Porto Alegre, v. 22, n. 37, p. 7-32, 1999.

MIRANDA, T.; HANAZAKI, N. Conhecimento e uso de recursos vegetais de restinga por comunidades das ilhas do Cardoso (SP) e de Santa Catarina (SC), Brasil. Acta Botanica Brasilica, Feira de Santana, v.22. n.1.p. 203-215, 2008.

ONU. Agenda 2030 para o Desenvolvimento Sustentável, 2015. Disponível em $<$ https://nacoesunidas.org/wp-content/uploads/2015/10/agenda2030-pt-br.pdf $>$ Acesso em 04 jun. 2020.

OROFINO, G.G; ROQUE, T.V.; FONSECA-KRUEL, V.S.; PERONI, N; HANAZAKI, N. Local knowledge about dugout canoes reveals connections between forests and fisheries. Environment, Development and Sustainability, v. 19, n. 1, p. 1-21, 2017. 
LUIJK, N. et al. Mulheres e a pesca artesanal: salvaguardando conhecimentos tradicionais sobre plantas da restinga em Arraial do Cabo, Brasil. Ethnoscientia v.6 n. 2, especial, 2021. DOI: 10.22276/ethnoscientia.v6i2.388

PRADO, S. M. Da anchova ao salário mínimo: uma etnografia sobre injunções de mudança social em Arraial do Cabo, RJ. Niterói: Eduff, 2002, 145p.

RIBEIRO, N.S.; NASCIMENTO, G. Guardiãs das tradições: mulheres da pesca em Arraial do Cabo - RJ. Revista Perspectivas Online: Humanas \& Sociais Aplicadas. Campos dos Goytacazes, v.10, n.29, p.20 -33, 2020.

RIO DE JANEIRO. 1985. Lei Estadual No 839 de 13 de maio de 1985, cria o município de Arraial do Cabo, a ser desmembrado do município de Cabo Frio. Disponível em $<$ https://govrj.jusbrasil.com.br/legislacao/149844/lei-839-85> Acesso em 25 mar. 2020.

ROSSATO, S. C.; LEITÃO FILHO, H. F.; BEGOSSI A. Ethnobotany of caiçaras of the Atlantic Forest Coast (Brazil). Economic Botany, Campinas, v.53, n. 4, p. 377-385, 1999.

SOUZA, T.M.K. O papel da mulher na Reserva Extrativista Marinha de Arraial do Cabo: uma análise através da Lógica Fuzzy. In: CALDASSO, L.P.; VALLE, R.; VINHA, V. (org). Governança em Reserva Extrativista Marinha. Rio de Janeiro: Pod Editora, p.73-86, 2012.

SOUZA, S.R.; RIBEIRO, N.S.; MARTÍNEZ, S.A. Mulheres em comunidades pesqueiras no Brasil: um balanço da produção de teses e dissertações (2007-2017). In: MARTÍNEZ, S.A.; HELLEBRANT, L. (orgs). Mulheres na atividade pesqueira no Brasil. Campos dos Goytacazes: EDUENF, 2019, p.21-50.

WILLIAMS, M. Why look at fisheries through a gender lens? Development, n.51. p.180-185, 2008.

WOORTMANN, ELLEN F. Da Complementaridade à Dependência: espaço, tempo e gênero em comunidades pesqueiras. Revista Brasileira de Ciências Sociais, São Paulo, n.18, 1992.

YODANIS, C. L. Constructing gender and occupational segregation: a study of women and work in fishing communities. Qualitative Sociology, n.23. p.267-290, 2000.

ZALUAR, A.; PIMENTEL, CRM. Rendeiras de bilro no estado do Rio de Janeiro. Rio de Janeiro: Divisão de Folclore, INEPAC, 1978, 48p.

ZHAO, M.; TYZACK, M.; ANDERSON, R.; ONOAKPOVIKE, E. Women as visible and invisible workers in fisheries: a case study of northern England. Marine Policy, Amsterdã, n.37. p.69-76, 2013. 